\title{
PERANCANGAN TATA KELOLA SISTEM INFORMASI MANAJEMEN RUMAH SAKIT (SIMRS) BERBASIS ITIL V3 \& SERVICE DESK STANDART (STUDI KASUS : RSUD KOTA KEDIRI)
}

\author{
Anita Sari Wardani \\ Program Studi Sistem Informasi \\ Universitas Nusantara PGRI Kediri \\ www.unpkediri.ac.id \\ anita@unpkediri.ac.id
}

\begin{abstract}
Minister of Health Regulation No. 82 of 2013 Chapter IV related to IT Governance recommends holding IT governance for SIMRS. IT governance by combining ITIL v3 and Service Desk Standard for hospitals has never been done. This study aims to design IT governance for SIMRS in the Kediri City Hospital according to ITIL v3 and Service Desk Standards. The design of IT governance is carried out after analyzing the gap of the current capability level with the target RSUD. The results of the IT governance design, 1 IT organizational structure, 11 IT processes, and 20 IT documents were successfully created and approved by the City Hospital of Kediri.
\end{abstract}

Keyword: IT Service, It Governance, Simrs

Intisari- Peraturan Menteri Kesehatan No 82 Tahun 2013 Bab IV terkait Tata Kelola TI merekomendasikan untuk mengadakan tata kelola TI untuk SIMRS. Tata kelola TI dengan mengabungkan ITIL v3 dan Service Desk Standar untuk rumah sakit belum pernah dilakukan. Penelitian ini bertujuan untuk merancang tata kelola TI untuk SIMRS di RSUD Kota Kediri sesuai ITIL v3 dan Service Desk Standar. Perancangan tata kelola TI dilakukan setelah melakukan analisa kesenjangan tingkat kapabilitas saat ini dengan target RSUD. Hasil rancangan tata kelola TI, 1 struktur organisasi TI, 11 proses TI, dan 20 dokumen TI berhasil dibuat dan disetujui oleh RSUD Kota Kediri.

Kata Kunci: Layanan TI, Simrs, Tata Kelola TI

\section{PENDAHULUAN}

Peraturan Menteri Kesehatan No 82 Tahun 2013 menyatakan bahwa setiap rumah sakit wajib menyelenggarakan Sistem Informasi Manajemen Rumah Sakit (SIMRS) untuk meningkatkan efisiensi, efektivitas, profesionalisme, kinerja, serta akses dan pelayanan rumah sakit. Peraturan ini merekomendasikan untuk menerapkan tata kelola TI untuk SIMRS (Kementerian Kesehatan Republik, 2013). Penerapan SIMRS agar sesuai dengan harapan stakeholder menuntut Rumah Sakit untuk membangun tata kelola TI untuk SIMRS yang baik (Hospital, Shalannanda, \& Hakimi, 2016).

Tata kelola TI adalah suatu wewenang dan tanggung jawab dari komisaris, direktur, dan manajer TI terkait dengan upaya memaksimalkan TI dalam menunjang strategi dan tujuan organisasi dengan memanfaatkan mekanisme struktural, mekanisme komunikasi dan proses tertentu (ITGI, 2009). (De Haes \& Van Grembergen, 2004) memberikan pandangan secara umum tentang komponen yang diperlukan untuk suksesnya tata kelola TI yaitu harus melibatkan struktur, proses, dan mekanisme relasional. Pengelolaan TI pada organisasi baik skala menengah atau besar tidak hanya menjadi urusan departemen TI saja namun kesuksesaan pengelolaan ini menjadi urusan seluruh stakeholder mulai dari dewan komisaris, top manajer, manajer fungsional, manajer operasional, manajer TI, dan karyawan sebagai end-user (Fasilkom, 2017)

Information Technology Infrastruktur Library (ITIL) merupakan salah satu framework tata kelola yang fokus pada pengelolaan siklus hidup layanan teknologi informasi (OGC, 2007). ITIL ini memberdayakan seluruh stakeholder layanan TI untuk melakukan hal yang benar dalam menyediakan layanan TI untuk mengoptimalkan pelayanan TI dalam mendukung pelayanan rumah sakit. Namun, ITIL tidak memiliki standar penilaian sendiri sehingga membutuhkan Service Desk Standart untuk menilai kinerja proses manajemen service desk dan komitmen peningkatan pelayanan terus-menerus (SDI, 2000).

Penelitian terkait pengelolaan TI dengan menerapkan berbagai praktek terbaik telah banyak dilakukan. Perancangan tata kelola TI dengan framework COBIT pada domain EDM dan DSS pernah dilakukan untuk mengatasi tidak meratanya jaringan internet yang buruk, penanganan insiden yang buruk dan pengadaan 
server yang tidak mendukung penggunaan aplikasi di BAPAPSI (Fajrin, Murahartawaty, \& Gumilang, 2017). Rancangan tata kelola yang dihasilkan dari penelitian ini meliputi struktur organisasi, prosedur dan panduan yang sesuai dengan kebutuhan.

Pelitian yang serupa pernah dilakukan dengan tujuan untuk membuat sebuah prosedur dan kebijakan agar layanan yang diberikan oleh Dinas Komunikasi dan Informatika Kota Bandung selalu maksimal. Hasil dari perancangan tata kelola ini adalah sebuah kebijakan TI dan 5 prosedur terkait proses-proses di ITIL yang menjadi prioritas (L. A. K. Wardani, Murahartawaty, \& Ramadani, 2017)

Penelitian terkait perancangan tata kelola TI tidak hanya dilakukan di bidang pemerintahan tapi juga di bidang pendidikan. (Udadhi Bawiko, Murahartawaty Murahartawaty, 2015) melakukan penelitian bertujuan untuk merancang tata kelola ITSM berdasarkan standar ISO 20000. Namun, kajian tentang tata kelola di bidang kesehatan khususnya rumah sakit sedikit dilakukan oleh akademisi (Fadilah \& Susanto, 2018). Aspek tata kelola TI juga kurang mendapat perhatian dari pihak manajemen rumah sakit. Oleh karena itu perlu dilakukan kajian terkait tata kelola SIMRS dari rumah sakit dengan mengabungkan framework ITIL v3 dan Service Desk Standar.

\section{BAHAN DAN METODE}

Metodologi penelitian merupakan acuan untuk melakukan tahap-tahap penelitian agar berjalan dengan baik. Dalam penelitian ini terdapat tahap identifikasi, analisa, perancangan, dan pengujian. Metodologi penelitian ditampilkan pada Gambar 1.

Tahap identifikasi proses TI dilakukan untuk mengetahui proses TI apa saja dari standar ITIL V3 dan Service Desk Standar yang akan digunakan untuk mengelola SIMRS. Kedua standar ini memberikan kebebasan pada organisasi untuk memilih proses TI mana saja yang akan digunakan. Analisa resiko dapat membantu organisasi memilih proses TI yang menjadi prioritas. Tahap analisa resiko dilakukan untuk mengetahui proses TI mana yang memiliki resiko tinggi, sedang, dan rendah berdasarkan penilaian tim counterpart TI jika proses tersebut tidak dijalankan. Proses - proses TI dengan resiko tinggi inilah yang akan dipilih dan diprioritaskan.

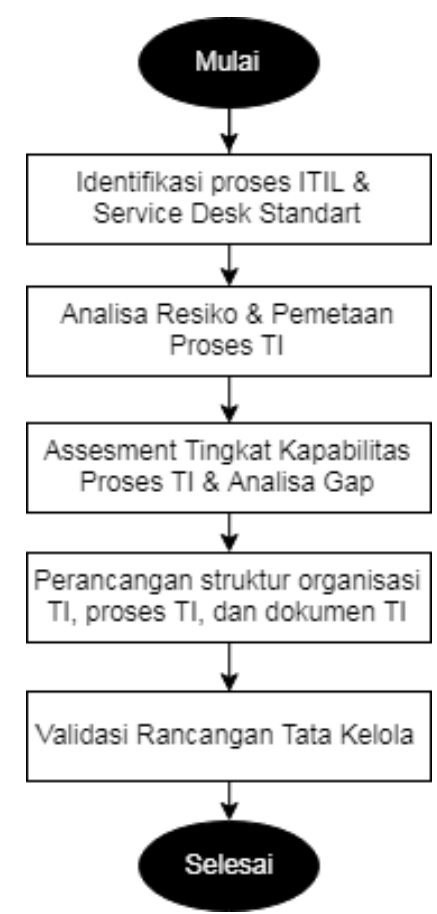

Sumber: (A. Wardani, 2019)

Gambar 1. Metodologi Penelitian

Tahap assessment tingkat kapabilitas proses TI dilakukan dengan menggunakan alat yang diadopsi dari ISO 15504. Tingkat kapabilitas TI diukur dari dua atribut proses yaitu base practise dan work product. Kuisioner penilaian terhadap pelaksanaan base practise dan work product akan dibagikan kepada tim counterpart TI di RSUD Kota Kediri. Responden dapat memilih salah satu skala penilaian, yaitu N-P-L-F. Dari hasil perhitungan skala penilaian seluruh responden akan diketahui level kapabilitas proses TI saat ini. Target level kapabilitas proses TI yang diharapkan oleh organisasi adalah level 2 (managed). Analisa kesenjangan dilakukan dengan membandingkan level kapabilitas saat ini dengan target yang diharapkan. Jika terdapat perbedaan maka terdapat gap yang menuntut pada perbaikan pengelolaan SIMRS.

Tahap perancangan struktur organisasi TI, proses TI, dan dokumen TI bertujuan menghasilkan rancangan tata kelola SIMRS yang dapat menghilangkan gap yang terjadi sehingga pengelolaan SIMRS dapat berjalan sesuai dengan standar pengelolaan TI. Tahap validasi rancangan tata kelola SIMRS dilakukan untuk mengetahui apakah rancangan tata kelola SIMRS sudah tepat dan sesuai dengan kebutuhan RSUD Kota Kediri atau tidak. Jika rancangan belum tepat dan tidak lolos validasi maka tahap perancangan akan dilakukan kembali hingga sesuai dan diterima oleh RSUD Kota Kediri. 


\section{HASIL DAN PEMBAHASAN}

Pada bagian ini akan dibahas hasil dan pembahasan penelitian.

\section{Identifikasi Proses TI \& Analisa Resiko}

Tabel 1 menampilkan hasil pemetaan identifikasi proses TI berdasarkan standar ITIL v3 dan Service Desk Sandart. Berdasarkan hasil analisa resiko, semua proses TI dinilai beresiko tinggi jika tidak dijalankan kecuali proses Manajemen Katalog Layanan TI yang dinilai beresiko sedang. Tabel 2 menunjukkan dampak yang akan terjadi jika proses TI tersebut tidak dijalankan oleh Rumah Sakit. Proses TI diklasifikasi beresiko tinggi apabila dampak yang

Tabel 1. Identifikasi Proses TI Dari ITIL v3 \& Service Desk Standart

\begin{tabular}{|c|c|c|}
\hline ITIL v3 & Service Desk Standart & Proses TI \\
\hline $\begin{array}{l}\text { Service } \\
\text { Catalogue } \\
\text { managem } \\
\text { ent }\end{array}$ & $\begin{array}{l}\text { Service Catalog } \\
\text { Management }\end{array}$ & $\begin{array}{ll}\text { Manajemen } & \text { Katalog } \\
\text { Layanan TI } & \end{array}$ \\
\hline $\begin{array}{l}\text { Service } \\
\text { Level } \\
\text { managem } \\
\text { ent }\end{array}$ & $\begin{array}{l}\text { Service Level } \\
\text { Management }\end{array}$ & $\begin{array}{ll}\text { Manajemen } & \text { Tingkat } \\
\text { Layanan TI } & \end{array}$ \\
\hline $\begin{array}{l}\text { Change } \\
\text { Managem } \\
\text { ent }\end{array}$ & IT Change Management & $\begin{array}{l}\text { Manajemen } \\
\text { Perubahan Layanan TI }\end{array}$ \\
\hline $\begin{array}{l}\text { Capacity } \\
\text { Managem } \\
\text { ent }\end{array}$ & $\begin{array}{l}\text { Capacity and } \\
\text { Availability }\end{array}$ & $\begin{array}{l}\text { Manajemen Kapasitas } \\
\text { Layanan TI }\end{array}$ \\
\hline $\begin{array}{l}\text { Release \& } \\
\text { Deployme } \\
\text { nt } \\
\text { Managem } \\
\text { ent }\end{array}$ & $\begin{array}{l}\text { Release and } \\
\text { Deployment } \\
\text { Management }\end{array}$ & $\begin{array}{l}\text { Manajemen Rilis } \\
\text { Layanan TI }\end{array}$ \\
\hline $\begin{array}{l}\text { Service } \\
\text { Asset \& } \\
\text { Configurat } \\
\text { ion } \\
\text { Managem } \\
\text { ent }\end{array}$ & $\begin{array}{l}\text { Confguration and Asset } \\
\text { Management }\end{array}$ & $\begin{array}{l}\text { Manajemen } \\
\text { Konfigurasi } \quad \text { Aset } \\
\text { Layanan TI }\end{array}$ \\
\hline $\begin{array}{l}\text { Request } \\
\text { Fulfilment }\end{array}$ & Request Fulfllment & $\begin{array}{l}\text { Manajemen } \\
\text { Permintaan Layanan } \\
\text { TI }\end{array}$ \\
\hline $\begin{array}{l}\text { Incident/ } \\
\text { Problem } \\
\text { Managem } \\
\text { ent }\end{array}$ & $\begin{array}{l}\text { Incident/ Problem } \\
\text { Management }\end{array}$ & $\begin{array}{l}\text { Pengelolaan Insiden \& } \\
\text { Permasalahan } \\
\text { Layanan TI }\end{array}$ \\
\hline $\begin{array}{l}\text { Access } \\
\text { managem } \\
\text { ent }\end{array}$ & Access Management & $\begin{array}{l}\text { Manajemen Akses } \\
\text { Layanan TI }\end{array}$ \\
\hline
\end{tabular}

Sumber: (A. Wardani, 2019) ditimbulkan menyebabkan ganguan operasional SIMRS yang mengakibatkan kerugian finansial yang besar sehingga membutuhkan perhatian khusus dari manajemen puncak dan harus segera diperbaiki. Klasifikasi resiko sedang apabila dampak yang ditimbulkan tidak signifikan terhadap operasional SIMRS sehingga hanya membutuhkan perhatian manajemen menengah dan ditindaklanjuti dalam jangka waktu menengah. Sedangkan resiko rendah apabila tidak berdampak terhadap operasional SIMRS sehingga dapat ditindaklanjuti oleh manajemen operasional dalam jangka panjang.

Tabel 2. Analisa Resiko \& Dampak Resiko

\begin{tabular}{|c|c|c|}
\hline Proses TI & Resiko & Dampak \\
\hline $\begin{array}{l}\text { Manajemen } \\
\text { Katalog } \\
\text { Layanan TI }\end{array}$ & Sedang & $\begin{array}{l}\text { Layanan TI tidak terdefinisi } \\
\text { sehingga kinerja tidak terukur }\end{array}$ \\
\hline $\begin{array}{l}\text { Manajemen } \\
\text { Tingkat } \\
\text { Layanan TI }\end{array}$ & Tinggi & $\begin{array}{l}\text { Layanan TI yang diberikan tidak } \\
\text { sesuai kebutuhan bisnis }\end{array}$ \\
\hline $\begin{array}{l}\text { Manajemen } \\
\text { Perubahan } \\
\text { Layanan TI }\end{array}$ & Tinggi & $\begin{array}{l}\text { Layanan TI dan infrastruktur TI } \\
\text { gagal menyediakan kapasitas } \\
\text { sesuai kesepakatan yang } \\
\text { dijanjikan (SLA/OLA) }\end{array}$ \\
\hline $\begin{array}{l}\text { Manajemen } \\
\text { Kapasitas } \\
\text { Layanan TI }\end{array}$ & Tinggi & $\begin{array}{l}\text { Layanan baru gagal memenuhi } \\
\text { kebutuhan bisnis }\end{array}$ \\
\hline $\begin{array}{l}\text { Manajemen } \\
\text { Rilis } \\
\text { Layanan TI }\end{array}$ & Tinggi & $\begin{array}{l}\text { Perilisan tidak sesuai jadwal } \\
\text { yang direncanakan }\end{array}$ \\
\hline $\begin{array}{l}\text { Manajemen } \\
\text { Konfigurasi } \\
\text { Aset } \\
\text { Layanan TI }\end{array}$ & Tinggi & $\begin{array}{l}\text { Aset TI, sistem TI, dan layanan TI } \\
\text { (CI) tidak terpantau }\end{array}$ \\
\hline $\begin{array}{l}\text { Manajemen } \\
\text { Permintaan } \\
\text { Layanan TI }\end{array}$ & Tinggi & $\begin{array}{l}\text { Gagal memprioritaskan } \\
\text { permintaan layanan TI }\end{array}$ \\
\hline $\begin{array}{l}\text { Manajemen } \\
\text { Insiden \& } \\
\text { Permasalah } \\
\text { an Layanan } \\
\text { TI }\end{array}$ & Tinggi & $\begin{array}{l}\text { User tidak mengikuti peraturan } \\
\text { dalam menggunakan } \\
\text { sistem/data }\end{array}$ \\
\hline $\begin{array}{l}\text { Manajemen } \\
\text { Akses } \\
\text { Layanan TI }\end{array}$ & Tinggi & $\begin{array}{l}\text { Insiden dan problem gagal } \\
\text { ditangani sesuai SLA }\end{array}$ \\
\hline
\end{tabular}

Sumber: (A. Wardani, 2019)

Assessment Tingkat Kapabilitas Proses TI \& Analisa Kesenjangan (Gap)

Proses - proses TI beresiko tinggi belum dilakukan oleh Rumah Sakit. Tingkat kapabilitas untuk semua proses TI masih pada level 0 (incomplete). Capaian atribut proses baik base practise atau work product masih berkisar 0-15\%. Tim counterpart TI belum menjalankan base practise dan work product sesuai standar. Hal ini disebabkan karena belum terbentuknya Instalasi 
Informasi \& Teknologi yang menghambat pegawai menjalankan base practise sesuai tugas dan fungsinya dalam organisasi.

Tabel 3 menunjukkan kesenjangan antara kondisi saat ini (eksisting) dengan kondisi target. Sesuai Peraturan Menteri Kesehatan No 82 Tahun 2013, pengelolaan SIMRS mestinya berada di bawah tanggung jawab sebuah fungsi/unit yang khusus menanggani teknologi informasi. Namun keadaan eksisting menunjukkan bahwa pengelola SIMRS saat ini ditanggani oleh sebuah tim. Akhibatnya proses - proses TI yang harusnya dijalakan tidak dapat dilakukan oleh sebuah tim. Sehingga harus segara ada upaya dari pihak manajemen untuk menghilangkan kesenjangan yang ada secepatnya.

Tabel 3. Analisa Kesenjangan (Gap)

\section{Struktur Organisasi TI}

\begin{tabular}{|c|c|}
\hline Target & Instalasi Informasi \& Teknologi \\
\hline Eksisting & Tim Counterpart TI SIMRS \\
\hline \multicolumn{2}{|r|}{ Proses TI } \\
\hline Target & Managed (Level 2), Largely/Fully Achieved \\
\hline Eksisting & $\begin{array}{l}\text { Incomplete (Level 0), Not Achieved (0-15\%) } \\
\text { 1. Manajemen Katalog Layanan TI } \\
\text { 2. Manajemen Tingkat Layanan TI } \\
\text { 3. Manajemen Perubahan Layanan TI } \\
\text { 4. Manajemen Kapasitas Layanan TI } \\
\text { 5. Manajemen Rilis Layanan TI } \\
\text { 6. Manajemen Konfigurasi Aset Layanan TI } \\
\text { 7. Manajemen Permintaan Layanan TI } \\
\text { 8. Manajemen Insiden \& Permasalahan } \\
\text { Layanan TI } \\
\text { 9. Manajemen Akses Layanan TI }\end{array}$ \\
\hline \multicolumn{2}{|r|}{ Dokumen Proses TI } \\
\hline Eksisting & $\begin{array}{l}\text { 1. Kebijakan TI } \\
\text { 2. Struktur Organisasi TI } \\
\text { 3. Panduan Pengelolaan TI } \\
\text { 4. Standar Operasional Prosedur (SOP) } \\
\text { Proses TI } \\
\text { 5. Dokumen/ Form Kerja }\end{array}$ \\
\hline Saat Ini & 1. Kebijakan TI \\
\hline
\end{tabular}

Sumber: (A. Wardani, 2019)

Perancangan Struktur Organisasi TI, Proses TI, dan Dokumen TI.

Struktur organisasi formal RSUD belum memuat instalasi yang memiliki fungsi dan tanggungjawab mengelola SIMRS. RSUD hanya menetapkan Tim Counterpart TI yang bertanggungjawab untuk mengelola TI. Tim Counterpart terdiri dari perwakilan setiap instalasi di RSUD yang telah menggunakan SIMRS dalam melakukan pelayanan kesehatan di Rumah Sakit. Kondisi ini tidak sesuai dengan Peraturan Menteri Kesehatan No 82 Tahun 2013 Bab IV tentang Tata Kelola SIMRS yang mewajibkan Rumah Sakit untuk memiliki Unit/Instalasi Informasi dan Teknologi.
Sehingga perlu segera menetapkan Instalasi Informasi dan Teknologi dan menetapkan struktur organisasi instalasi informasi dan teknologi dengan tugas, dan tanggungjawab masing-masing. Rancangan Struktur Organisasi TI dapat dilihat pada Gambar 2. Dari struktur ini akan ditetapkan penanggung jawab pelaksana masing-masing proses TI dalam mengelola SIMRS.

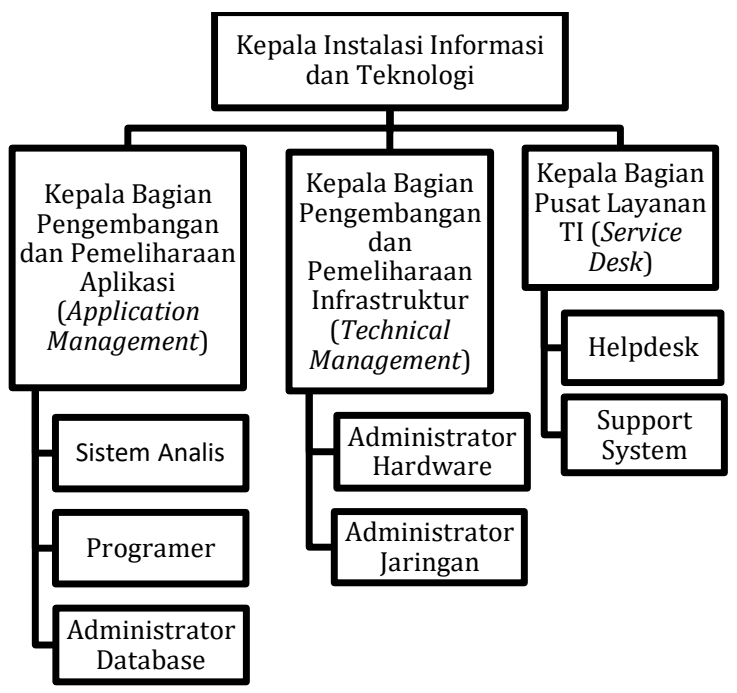

Sumber: (A. Wardani, 2019)

Gambar 2 Rancangan Struktur Instalasi Informasi \& Teknologi

Tabel 4 menampilkan tugas dan tanggung jawab dari masing-masing bagian untuk melaksanakan proses-proses TI untuk mengelola SIMRS. Bagian Pengembangan dan Pemeliharaan Aplikasi bertanggungjawab terhadap berjalannya manajemen katalog layanan $\mathrm{TI}$, tingkat layanan $\mathrm{TI}$, perubahan layanan TI, rilis layanan TI, dan akses layanan TI. Bagian Pengembangan dan Pemeliharaan Infrastruktur bertanggungjawab terhadap berjalannya manajemen katalog layanan TI, perubahan layanan TI, kapasitas layanan TI, dan konfigurasi aset layanan TI. Sedangkan bagian Service Desk bertangungjawab terhadap berjalannya manajemen permintaan layanan TI dan insiden serta permasalahan layanan TI.

Tabel 4. Tugas \& Tanggung Jawab Organisasi TI

\begin{tabular}{llll}
\multicolumn{1}{c}{ Proses TI } & AP & TM & SS \\
\hline Manajemen Katalog Layanan TI & & & \\
\hline Manajemen Tingkat Layanan TI & & & \\
\hline Manajemen Perubahan Layanan TI & & & \\
\hline Manajemen Kapasitas Layanan TI & & & \\
\hline Manajemen Rilis Layanan TI & & & \\
\hline
\end{tabular}




\begin{tabular}{l}
\hline Manajemen Konfigurasi Aset Layanan \\
TI \\
\hline Manajemen Permintaan Layanan TI \\
\hline Manajemen Insiden \& Permasalahan \\
Layanan TI \\
\hline Manajemen Akses Layanan TI \\
Sumber: (A. Wardani, 2019) \\
AP = Application Management \\
TM = Technical Management \\
SS = Service Desk
\end{tabular}

Untuk menjalankan proses TI dengan baik dibutuhkan panduan, standar operasional prosedur, dan template/form isian kerja. Berikut adalah daftar rancangan dokumen TI yang digunakan dalam pengelolaan SIMRS :

1. Panduan Pengembangan Aplikasi \& Infrastruktur TI

2. Panduan Pemeliharaan Aplikasi \& Infrastruktur TI

3. Panduan Pengadaan Aplikasi \& Infrastruktur TI

4. Panduan Penanganan Insiden \& Permasalahan Layanan TI

5. Panduan Back Up \& Recovery Data

6. Panduan Kemamanan SIMRS

7. Standar Operasional Prosedure (SOP) Pengelolaan Katalog Layanan TI

8. Standar Operasional Prosedure (SOP) Perubahan Layanan TI

9. Standar Operasional Prosedure (SOP) Rilis \& Konfigurasi Layanan TI

10. Standar Operasional Prosedure (SOP) Insiden \& Pemasalahan Layanan TI

11. Standar Operasional Prosedure (SOP) Manajemen Akses Layanan TI

12. Template Dokumen Katalog Layanan TI

13. Template Form Permintaan Layanan TI

14. Template Form Permintaan Perubahan Layanan TI

15. Template Laporan Permintaan Perubahan Layanan TI

16. Template Daftar Aset \& Konfigurasi Layanan TI

17. Template Dokumen Rencana Rilis \& Konfigurasi Layanan TI

18. Template Form Insiden \& Permasalahan Layanan TI (Ticket Incident)

19. Template Laporan Insiden \& Permasalahan Layanan TI

20. Template Laporan Evaluasi Akses Layanan TI

Validasi Rancangan Tata Kelola TI untuk SIMRS. Semua rancangan tata kelola TI untuk SIMRS dari struktur organisasi TI, proses TI hingga dokumen TI divalidasi oleh tim counterpart TI RSUD Kota Kediri dengan form validator yang memastikan bahwa rancangan tata kelola TI untuk SIMRS telah sesuai dengan Peraturan Menteri Kesehatan No 82 Tahun 2013, standar ITIL v3 dan Service Desk Standar, dan kebutuhan RSUD Kota Kediri. Tim counterpart TI menyatakan bahwa rancangan tata kelola TI untuk SIMRS telah sesuai dengan peraturan, standar, dan kebutuhan RSUD Kota Kediri.

\section{KESIMPULAN}

Rancangan tata kelola TI untuk SIMRS di RSUD Kota Kediri yang telah dibuat terdiri dari 1 struktur organisasi $\mathrm{TI}, 11$ proses $\mathrm{TI}$, dan 20 dokumen TI. Struktur organisasi TI terdiri dari kepala instalasi informasi \& teknologi, 3 kepala bagian (aplikasi, hardware \& Jaringan, service desk) dan 7 roles (sistem analis, programer, administrator database, administrator hardware, administrator jaringan, helpdesk, dan support system). Terdapat 11 proses TI yang tugas dan tanggungjawabnya dilakukan oleh ketiga bagian instalasi informasi \& teknologi. Dokumen TI terdiri dari 6 panduan, 5 standar operasional prosedur, 10 template/form isian kerja. Semua rancangan tata kelola TI untuk SIMRS telah disetujui oleh Tim Counterpart TI RSUD Kota Kediri.

\section{REFERENSI}

De Haes, S., \& Van Grembergen, W. (2004). IT Governance and its Mechanisms. Information Systems Control Journal, 1, 27-33. https://doi.org/citeulike-article-id:9755150

Fajrin, R. A., Murahartawaty, M., \& Gumilang, S. F. S. (2017). Perancangan Tata Kelola Teknologi Informasi di BAPAPSI Pemkab Bandung Menggunakan framework COBIT 5 Pada Domain EDM dan DSS. Journal of Information Systems Engineering and Business Intelligence, 2(2), 74. https://doi.org/10.20473/jisebi.2.2.74-80

Fasilkom. (2017). Modul Perkuliahan Tata Kelola IT.

Hospital, C. S. X., Shalannanda, W., \& Hakimi, R. (2016). IT Governance Design for Hospital Management Information System. 10th International Conference on Telecommunication Systems Services and Applications (TSSA).

ITGI. (2009). IT Governance Round Table: defining IT Governance. Governance An International Journal of Policy And Administration. 
Kementerian Kesehatan Republik. Peraturan Menteri Kesehatan Republik Indonesia Nomor 82 Tahun 2013 tentang Sistem Informasi Manajemen Rumah Sakit (2013).

OGC. (2007). The Official Introduction to the ITIL Service Lifecycle. Online (Vol. 69). https://doi.org/citeulike-article-id:2420971

SDI. (2000). The Service Desk Standard.

Udadhi Bawiko, Murahartawaty Murahartawaty, M. S. (2015). Perancangan Tata Kelola Manajemen Layanan Teknologi Informasi Berdasarkan Iso 20000 Dan Itil V3 Service Design Pada Layanan Sistem Informasi Akademik Igracias.

Wardani, A. (2019). Laporan Akhir Penelitian: Perancangan Tata Kelola Sistem Informasi
Manajemen Rumah Sakit Berbasis ITIL v3 \& Service Sesk Standart (Studi Kasus: RSUD Kediri). Kediri.

Wardani, L. A. K., Murahartawaty, M., \& Ramadani, L. (2017). Perancangan Tata Kelola Layanan Teknologi Informasi Menggunakan ITIL versi 3 Domain Service Transition Dan Service Operation Di Pemerintah Kota Bandung. Journal of Information Systems Engineering and Business Intelligence, 2(2), 81. https://doi.org/10.20473/jisebi.2.2.81-87 